\title{
O Setor Calçadista do Vale dos Sinos/ Rs: Um Estudo a partir do Modelo Estrutura-Conduta-Desempenho
}

Herton Castiglioni Lopes ${ }^{1}$

\begin{abstract}
Resumo: O trabalho tem como objetivo realizar um estudo do setor calçadista do Vale dos Sinos/RS a partir do modelo Estrutura-Conduta-Desempenho (E-C-D). Para isso, foram utilizadas informações de fonte secundária, como publicações sobre o assunto, e dados primários, referentes à aplicação de questionários às empresas da região do Vale dos Sinos/RS cadastradas na Abicalçados. Quanto à estrutura, observou-se queda no grau de concentração da indústria no estado. Já nas empresas do Vale dos Sinos/RS constataram-se baixas barreiras à entrada, mas com necessidade de grandes investimentos e uma alta escala produtiva para que as firmas possam concorrer no mercado. É uma indústria diversificada, com baixa ocorrência de integração vertical e com produtos diferenciados, mas em que as estratégias de redução de custos tem sido prioridade para os empresários. Observaram-se significativos esforços por parte das empresas no sentido de melhorar o desempenho de mercado, altamente prejudicado devido às políticas macroeconômicas e ao ambiente concorrencial que se formou nos últimos anos.
\end{abstract}

Palavras-Chave: Estrutura-Conduta-Desempenho, Indústria Calçadista, Vale dos Sinos/RS.

JEL: L10 


\section{The Shoe Industry of Vale dos Sinos (Rs): an Study From the Structure-Conduct- \\ Performance Model}

Abstract: This paper aims to do a study on the footwear sector in Vale dos Sinos/RS from the Structure-Conduct-Performance $(S-C-P)$ model. We used information from secondary sources, such as publications on the topic, and from primary sources, i.e, the application of questionnaires to companies in the region of Vale dos Sinos/ $R S$ which are registered at Abicalçados. Concerning the structure, we observed $R S$ which are registered at Abicalçados. Concerning the structure, we observed in Vale dos Sinos/RS, we noticed few obstacles to the entry of shoes, but the need of great investments and a high scale of production for the companies to compete in the market. It is a diversified factory with low vertical integration and with different goods, but where the strategy of costs reduction has been a priority for the businessmen. We observed significant efforts from the companies to improve market development, which is damaged by the macrostructural policies and by the concurrence from the last years.

Keywords: Structure-Conduct-Performance, Footwear Industry, Vale dos Sinos/ $R S$.

JEL: L10

\section{Introdução}

O setor calçadista gaúcho sempre mereceu especial atenção, seja por parte dos estudiosos de indústrias, seja das autoridades governamentais da região. A preocupação com o setor ocorre em função da importância econômica que o mesmo desempenha para o estado. Trata-se de uma indústria tradicional, reconhecida no mercado externo e que gera uma quantidade significativa de empregos, em especial nas regiões com maior concentração geográfica de fábricas. Por ser voltada para o mercado externo, a indústria é uma grande geradora de divisas para o mercado brasileiro. $O$ estado gaúcho ainda abriga um dos maiores clusters produtores de calçados do mundo, que está localizado na região do Vale dos Sinos (Vargas; Alievi, 2000).

Como será demonstrado na seqüência, apesar do retrospecto historicamente favorável da indústria, nos últimos anos o setor vem passando por alguma dificuldades. Os problemas decorrem principalmente da maior concorrência que se estabeleceu tanto no mercado nacional como internacional. Além disso, nos períodos mais recentes, a valorização do câmbio brasileiro tem sido um fator determinante no desempenho da indústria que, por ser essencialmente exportadora, sofre com as flutuações da moeda norte-americana. Com esses problemas, muitas empresas têm buscado melhores condições produtivas, deixando o estado para obterem menores custos de produção.

É diante da importância econômica do setor calçadista e devido ao cenário perverso que se consolidou nos últimos anos que esse trabalho objetiva realizar um diagnóstico do setor calçadista do Vale dos Sinos/RS, utilizando-se do modelo Estrutura-Conduta-Desempenho' ${ }^{1}$. A partir dessa análise será possível observar a organização atual da indústria, bem como os principais condicionantes do seu desempenho. Convém destacar que o referido modelo, embora tenha perdido espaço para novas abordagens ${ }^{2}$, contempla praticamente todos os aspectos necessários para o adequado diagnóstico do setor em questão, servindo para avaliação de fatores cruciais para indústria, ou seja, os que realmente exercem maior impacto sobre sua competitividade.

Visando apresentar um diagnóstico da indústria, além de dados secundários relacionados à indústria calçadista gaúcha, foram aplicados questionários às empresas do Vale dos Sinos/RS que se encontravam cadastradas na Associação Brasileira de Indústrias de Calçados (Abicalçados). Para completar a análise em termos de sua Estrutura, Conduta e Desempenho, além dos dados referentes à indústria de calçados do Rio Grande do Sul e das informações obtidas mediante a aplicação dos questionários, procurou-se pesquisar informações em publicações sobre a indústria e confrontar as mesmas com os resultados encontrados.

Enfim, para atingir os objetivos propostos, além dessa introdução, o trabalho apresenta-se assim dividido: o item 1 apresenta o Modelo Estrutura-Conduta-Desempenho, tratando de sua origem e das variáveis que o mesmo contempla. O item 2 trata da metodologia utilizada para realização do trabalho, enquanto o item 3 traz a aplicação do modelo E-C-D ao setor calçadista do Vale dos Sinos/ RS. Por fim, são apresentadas as principais conclusões do trabalho (item 4).

\section{O Modelo Estrutura-Conduta-Desempenho}

O modelo Estrutura-Conduta-Desempenho (E-C-D) é um instrumento oriundo da Organização Industrial. Seu objetivo, segundo Scherer e Ross (1990), é estudar as variáveis que influenciam no desempenho econômico, permitindo a construção de teorias que detalhem a ligação entre essas variáveis e o desempenho da indústria. Cabral (1994), por sua vez, afirma que o modelo E-C-D é

10 modelo apresenta como fatores importantes de análise as condicões básicas de oferta e demanda, assim como as políticas públicas que afetam a indústria. Contudo, o estudo proposto na sequiênncia enfoca principalmente a Estrutura, a Conduta e o Desempenho da indústria em questão, mesmo tendo presente o papel

2 qu desempenham de diagnóstico industrial de Porter (1986) e Ferraz et. al. (1997) são exemplos de referenciais teóricos muito utilizados no diagnóstico industrial, em especial quando se referem à análise da competitividade.

Revista de Economia, v. 40, n. 3 (ano 38), p. 68-90, set/dez. 2014. Editora UFPR 
um paradigma que fornece um esquema para análise de mercados. O modelo permite a sistematização e articulação dos diversos aspectos relevantes para análise da indústria e do seu eventual poder de mercado.

Sobre o desenvolvimento histórico do modelo E-C-D, tem-se que sua concepção é atribuída a Mason e a seus colegas de Harvard. Segundo Holanda Filho (1983), Mason é o pioneiro em trabalhos que procuram investigar a relação de causalidade entre Estrutura-Comportamento-Desempenho. Ainda, segundo o autor, estudos que utilizam este modelo visam relacionar variáveis que meçam aspectos da estrutura de mercado (concentração, diferenciação, barreiras à entrada, etc.) com o comportamento das empresas (política de preços, pesquisas e inovações, propaganda, etc.), e este com variáveis do desempenho (tais variáveis procuram refletir a eficiência na adoção de novas técnicas, progresso econômico, etc.).

Apesar de ser Mason o pioneiro em trabalhos deste tipo, segundo Holanda Filho (1983), é Joe Bain (1968) que se destaca com trabalhos mais detalhados e ricos dentro desta linha. E este autor quem, durante a década de 50, iniciou a formalização teórica do modelo, fazendo em seu livro Industrial Organization um estudo individual de cada um dos elementos que o compõe, para depois fazer uma análise teórico-empírica sobre as associações entre seus elementos.

Os trabalhos iniciais utilizando o modelo E-C-D procuravam estabelecer uma relação de causalidade entre as variáveis. Ou seja, o modelo foi concebido procurando observar uma relação entre a estrutura e o desempenho de mercado. Nesses termos, acreditava-se que quanto mais concentrada uma estrutura industrial maior o desempenho das empresas. $\mathrm{O}$ foco principal era, ao avaliar tal relação de causalidade, evidenciar os casos em que firmas com elevado poder de mercado pudessem adotar práticas anticompetitivas e prejudiciais ao bem estar da sociedade.

Ao priorizarem essa relação, os trabalhos negligenciavam outros aspectos que podiam afetar significativamente o desempenho das empresas. Atualmente, contudo, admite-se que além de variáveis da estrutura, diversas outras podem ser relevantes para estudar o desempenho industrial. Além disso, também se admite $\mathrm{o}$ inter-relacionamento entre as variáveis do modelo, de forma que 0 mesmo abandona, em parte, seu caráter estático (foco de muitas críticas) e passa e incorporar feed-backs entre os elementos.

A figura 1 apresenta o modelo E-C-D proposto por Carlton e Perloff (1994), nele ficando clara a amplitude desse marco teórico, assim como as inter-relações entre as variáveis consideradas.
FIGURA 1 - O MODELO ESTRUTURA-CONDUTA-DESEMPENHO

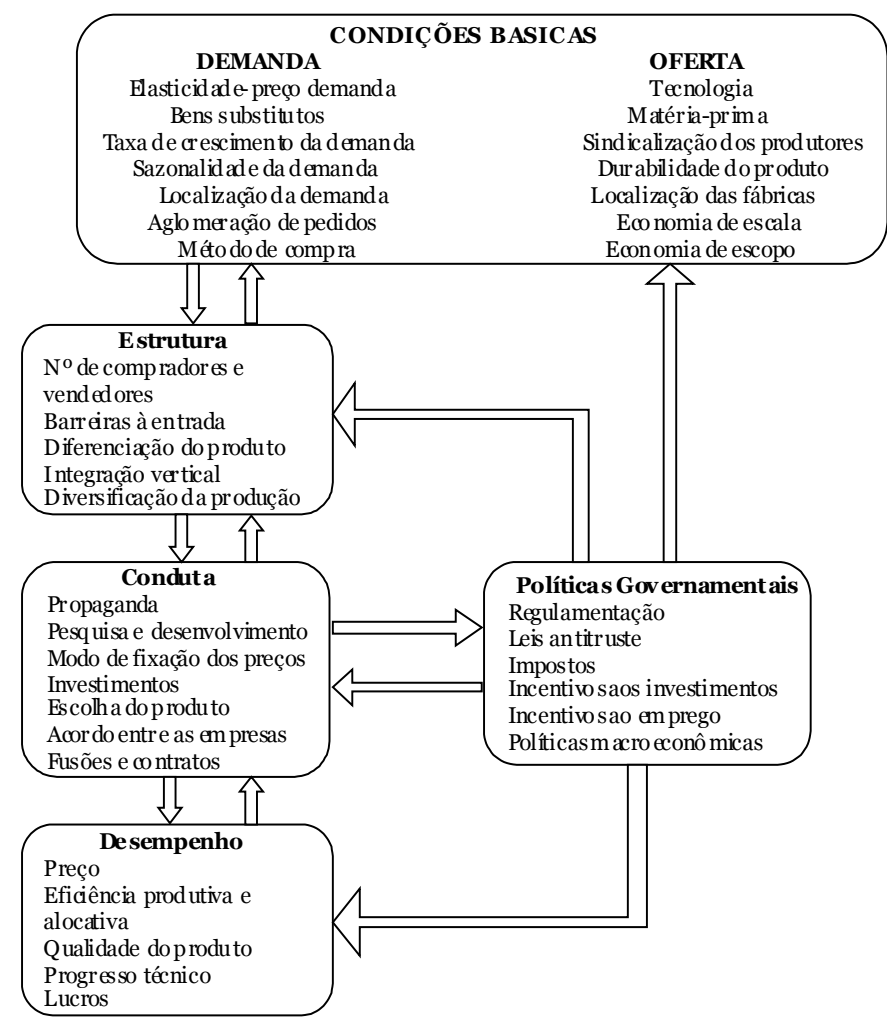

Fonte: Adaptado de Carlton e Perloff (1994)

Sobre as relações entre variáveis, atualmente admite-se que a própria estrutura de mercado pode ser determinada endogenamente. Portando, embora o modelo tenha sido concebido com uma visão bastante limitada sobre os determinantes do desempenho industrial, observa-se que seus constantes aperfeiçoamentos o transformaram em um modelo capaz de fornecer subsídios para estudos detalhados e aprofundados sobre indústrias. Convém destacar ainda que o modelo é facilmente adaptável a diversos tipos de trabalhos, pois fornece um corpo analítico para os diferentes tipos de análises e enfoques propostos. Quer-se dizer com isso que quaisquer tipos de variáveis que se deseje analisar podem ser facilmente incorporadas a elementos da estrutura, da conduta, do desempenho, ou ainda incluídas nas políticas públicas ou condições básicas de oferta e demanda.

Assim sendo, embora alguns autores como Porter (apud ROSA, 2001), apre- 
sentem a importância de modelos que incorporem a empresa em um caráter dinâmico, de forma alguma isso desmerece o marco teórico aqui considerado, pois o mesmo não pode ser tratado como um modelo estático, principalmente a partir dos seus aperfeiçoamentos. Nesses termos, podemos citar vários exemplos de inter-relacionamento entre as variáveis. Os grandes esforços de pesquisa e desenvolvimento (P\&D) realizados por uma firma (variável da conduta), podem alterar a tecnologia predominante na indústria, a estrutura de custos e o grau de diferenciação física do produto. Outro exemplo é que políticas de determinação de preços podem encorajar a entrada de novas firmas no mercado ou expulsar firmas mais fracas, alterando, conseqüentemente, a estrutura de mercado.

A seguir apresentam-se algumas considerações sobre a estrutura, a conduta e o desempenho de mercado. Apesar das diversas variáveis que estão presentes em cada um desses elementos, convém destacar que as mesmas serão apresentadas de forma mais específica no estudo do setor calçadista do Vale dos Sinos/RS.

\subsection{Estrutura de Mercado}

A estrutura de mercado diz respeito às características de organização que parecem influenciar estrategicamente a natureza da competição e os preços dentro de determinado mercado, ou seja, a estrutura refere-se à maneira como as empresas que integram uma indústria se organizam. Para Bain (1968) as características determinantes da estrutura de mercado são relativas e tendem a não sofrer alterações expressivas em curto espaço de tempo. Desta forma, a estrutura é relativamente estável no curto prazo, mas pode se modificar em períodos de longo prazo devido à dinâmica das relações industriais.

No modelo E-C-D a estrutura de mercado é definida de acordo com as variáveis que a compõe. Seguindo modelo de Carlton e Perloff (1994), essas variáveis são: o número de compradores e vendedores, as barreiras à entrada, a diferenciação do produto, a integração vertical e a diversificação da produção. Convém destacar que o número de compradores e vendedores se relaciona diretamente com a concentração de mercado, pois, de certa forma, pode-se dizer que existe uma relação inversa entre o grau de concentração de mercado e a concorrência, fato que será analisado na indústria pesquisada.

\subsection{Conduta ou estratégias de mercado}

A conduta está relacionada às ações das firmas para operar no mercado, razão pela qual pode ser tratada como sinônimo de estratégia competitiva. Trata-se do processo de escolha entre diferentes alternativas de decisão quanto a variáveis que estão sob controle da empresa.

De acordo com Kupfer (1992), a conduta das empresas era negligenciada nas primeiras versões do E-C-D. Isso ocorria porque os elementos estruturais, principalmente a concentração de mercado, eram vistos como os principais responsáveis pelo desempenho. Contudo, as versões mais atuais do modelo consideram a importância da conduta, pois admitem que a mesma, além de influenciar no desempenho, pode alterar a própria estrutura industrial.

Ao admitir-se a importância desses feed-backs, aceita-se que as estratégias podem influenciar de forma mais significativa o processo de concorrência e conclui-se que as firmas possuem um papel ativo nas transformações ocorridas no ambiente concorrencial. Dependendo do mercado que se está considerando, as firmas podem ser as responsáveis por alterações no padrão de concorrência, pois, ao invés de simplesmente se adaptarem ao mercado onde operam, também podem estabelecer ações capazes de modificá-lo.

\subsection{Desempenho de mercado ou competitivo}

O desempenho de mercado é um resultado da conduta das empresas, influenciado pela estrutura de mercado, políticas públicas e condições básicas de oferta e demanda. Trata-se de uma variável ex-post facto, ou seja, avaliada apenas após ter acontecido (Scherer; Ross, 1990).

Scherer e Ross (1990) consideram o desempenho como um fator multidimensional que engloba diversos elementos, tais como: as decisões sobre o que, quanto e como produzir, que devem ser eficientes; as operações dos produtores que devem tirar vantagem da tecnologia e facilitar o emprego total de recursos e; a distribuição de renda que deve ser equitativa, implicando que a remuneração dos produtores não seja excessiva.

Apesar dos diversos aspectos considerados para avaliação do desempenho, cabe considerar que os mais relevantes dependem do setor a ser analisado. É comum, na avaliação do desempenho industrial, enfocar aspectos financeiros. Contudo, no caso do setor calçadista, foram consideradas as variáveis que oferecem um diagnóstico global da indústria, ao invés de procurarem-se relações de causalidade entre as mesmas. 


\section{Metodologia}

\subsection{Classificação da pesquisa}

A pesquisa pode ser considerada, na definição proposta por Gil (1999), como uma pesquisa do tipo exploratória, pois procura desenvolver, esclarecer e modificar conceitos e idéias, tendo em vista a formulação de problemas mais precisos ou hipóteses pesquisáveis para estudos posteriores. Em síntese, pode ser considerada como exploratória porque procura, a partir de um referencial teórico estabelecido, fazer uma caracterização da indústria calçadista e das principais variáveis que compõem sua estrutura, sua conduta e seu desempenho.

\subsection{Fontes utilizadas}

A análise das variáveis apresentadas no modelo E-C-D foi feita considerando as características do setor produtor de calçados. Para tanto, foram utilizados dados secundários tais como publicações sobre a indústria pesquisada e informações constantes no Cadastro Empresarial do Rio Grande do Sul e Associação Brasileira das Indústrias de Calçados (Abicalçados).

Para análise da concentração de mercado, variável fundamental da estrutura, foram utilizadas as informações coletadas do Cadastro Empresarial do Rio Grande do Sul. Estas informações referem-se ao número de empregados por empresa que serviram para o cálculo dos índices de concentração no setor. São a razão de concentração (Cr) e Herfindahl-Hirschman (HHI), calculados da seguinte forma:

a) Razão de concentração (Cr)

$$
C r(k)=\sum_{i=1}^{k} P i
$$

onde:

$k=$ número de firmas que fazem parte do cálculo;

$P i=$ participação da i-ésima firma no mercado.

Este índice mede a proporção representada por um número fixo das maiores empresas de uma indústria em relação ao total desta indústria. Possui fácil interpretação, pois varia de o a 100. Quanto mais próximo estiver de 100, maior é a concentração na indústria. Ou seja, quando um número pequeno de firmas é responsável por uma grande proporção da produção, das vendas ou do emprego da indústria, então a concentração é alta (Resende; Boff, 2002).

b) Índice de Herfindahl-Hirschman $(\mathrm{HH})$

$$
H H=\sum_{i=1}^{n} P i^{2}
$$

onde:

$n=$ número de firmas no mercado;

$P i=$ participação da i-ésima firma no mercado.

O índice HH define-se pela soma dos quadrados da participação de cada firma em relação ao tamanho total da indústria e, ao contrário da razão de concentração, leva em conta todas as firmas da indústria. Este índice assume o valor máximo 1 (um), quando existe apenas uma empresa na indústria (monopólio) e assume seu valor menor, $1 / \mathrm{n}$, quando as firmas têm participação igualitária no mercado. $\mathrm{O}$ valor de $\mathrm{HH}$ aumenta conforme aumenta a desigualdade entre as firmas pertencentes à indústria, apresentando-se, desta forma, como um bom indicador da situação de mercado (Resende; Boff, 2002).

Para análise das demais variáveis que compõem a estrutura e conduta da indústria foram utilizadas informações referentes a publicações que caracterizam a indústria calçadista, em conjunto com questionários que foram aplicados às empresas fabricantes de calçados do Vale dos Sinos/RS. No que diz respeito ao desempenho de mercado, foram utilizados dados referentes à indústria calçadista gaúcha e coletados junto a Abicalçados.

\subsection{A pesquisa de campo}

Para obtenção das informações relativas às variáveis da estrutura (exceto a concentração) e da conduta de mercado, foram enviados questionários as empresas calçadistas situadas na Região do Vale dos Sinos, cadastradas na Abicalçados. Procurou-se que o responsável pelas respostas estivesse ligado à direção da empresa, possuindo conhecimento global das atividades realizadas.

Para delimitação da região do Vale dos Sinos, adotou-se a classificação institucional utilizada pelo Conselho Regional de Desenvolvimento (Corede), que abrange quatorze municípios do estado, sendo eles: Araricá, Campo Bom, Ca- 
noas, Dois Irmãos, Estância Velha, Esteio, Ivoti, Nova Hartz, Nova Santa Rita, Novo Hamburgo, Portão, São Leopoldo, Sapiranga e Sapucaia do Sul (FEE 2012). Do total de 43 empresas que constavam no cadastro da Abicalçados, 37 eram fabricantes, enquanto seis tratavam-se de agentes de exportação. Das 37 empresas, obteve-se um total de 18 respostas, as quais foram utilizadas na análise. Cabe mencionar que a maior parte das empresas são, segundo a classificação proposta pelo SEBRAE (2010) ${ }^{3}$, empresas de médio e grande porte, sendo 8 grandes, 8 médias e apenas 2 pequenas.

\section{O Caso do Setor Calçadista do Vale dos Sinos: A aplica-} ção do Modelo E-C-D

A partir da análise das variáveis apresentadas no modelo E-C-D pode-se realizar um diagnóstico do setor calçadista do Vale dos Sinos e, em geral, do Rio Grande do Sul. Portanto, a seguir apresenta-se uma análise das variáveis da estrutura, da conduta e do desempenho do setor calçadista.

\subsection{Estrutura de Mercado}

a) Concentração: a concentração de mercado é o elemento principal de uma estrutura industrial e, segundo Resende e Boff (2002), sua medida pretende fornecer um indicador sintético da concorrência existente em um mercado. A análise a seguir foi realizada para indústria calçadista do estado e apresenta os índices de concentração nos anos de 1991, 1998 e 2008. Os índices foram calculados a partir do número de empregados por empresa disponível no cadastro empresarial do Rio Grande do Sul.

TABELA 1: INDICADORES DE CONCENTRAÇÃO NO SETOR CALÇADISTA GAÚCHO

\begin{tabular}{c|ccc}
\multicolumn{2}{l}{ GAUCHO } \\
$\begin{array}{c}\text { Índice de Con- } \\
\text { ce n t r a ç ã o / } \\
\text { Ano }\end{array}$ & $\mathbf{1 9 9 1}$ & $\mathbf{1 9 9 8}$ & $\mathbf{2 0 0 8}$ \\
\hline $\mathrm{Cr} 4$ & $16 \%$ & $21 \%$ & $19 \%$ \\
$\mathrm{HH}$ & 0,0142 & 0,021 & 0,018 \\
\hline
\end{tabular}

Fonte: Elaboração própria a partir do cadastro empresarial do RS dos anos de 1991, 1998 e 2008.

A tabela 1 mostra que o índice $\mathrm{Cr}_{4}$ sofreu aumento de $16 \%$ para $21 \%$ de 1991 para 1998, reduzindo-se em 2008, quando atinge $19 \%$. O índice $\mathrm{HH}$ evoluiu

3 O SEBRAE considera como microempresa (na indústria), a que possui de o (zero) a 19 empregados; pequena empresa, a que possui de 20 a 99 empregados; média empresa, a que possui de 100 a 499 empregados; de forma semelhante, pois em 1991 encontrava-se em 0,0142 passando para 0,021 em 1998 e voltando a reduzir-se para 0,018 em 2008. Apesar das oscilações apresentadas pelos índices, podemos classificar o setor como pouco concentrado, pois, segundo Bain (1968), uma indústria que apresenta uma razão de concentração, para as quatro maiores empresas, inferior a $25 \%$, pode ser classificada como uma indústria atomística.

b) Barreiras à entrada: quando uma nova empresa deseja entrar em uma indústria, normalmente ela se depara com alguns empecilhos que, segundo Kon (1994), são inerentes à condição de entrada no mercado. Na pesquisa aplicada junto aos fabricantes de calçados, considerou-se a possibilidade de diversas barreiras e pediu-se que os empresários atribuíssem notas de zero a 10 para as dificuldades de entrada na indústria (notas maiores representam maiores barreiras). O gráfico a seguir apresenta as notas médias atribuídas pelos empresários às barreiras à entrada no setor.

FIGURA 2: BARREIRAS A ENTRADA NO SETOR CALÇADISTA DO VALE DOS SINOS/RS

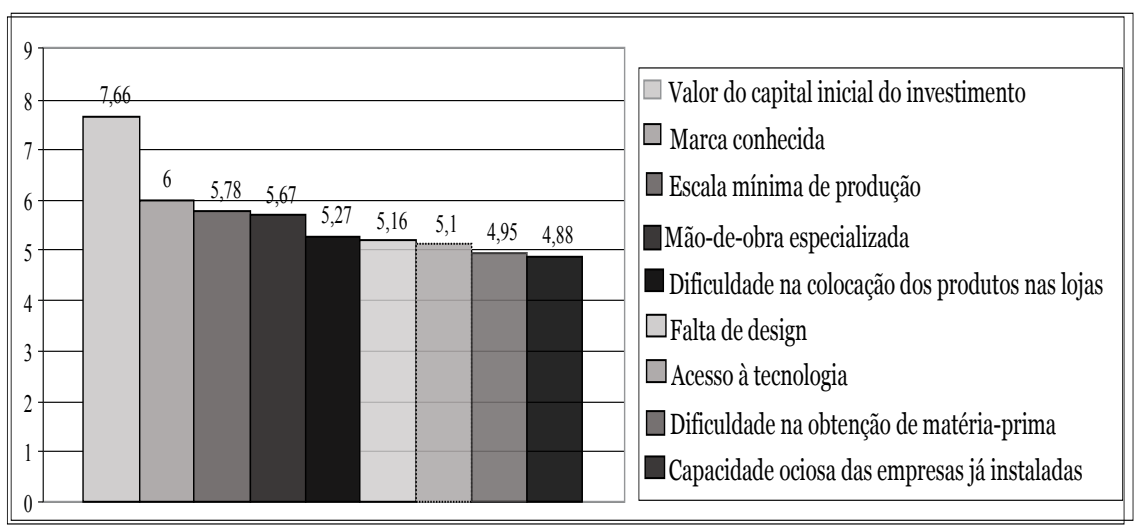

Fonte: pesquisa de campo

Apesar do valor do capital inicial investido para fabricar calçados ser considerado relativamente baixo por Gorini et. al.(2000) e Lemos e Palhano (2000), surpreendentemente, este foi o empecilho que recebeu a nota média mais elevada $(7,66)$. Tal resultado apresenta relação com o porte das empresas pesquisadas, pois, por serem, em sua maioria, grandes e médias, são influenciadas por sua escala produtiva. Portanto, pode-se dizer que, na percepção dos empresários, para começar a fabricação de calçados, é preciso realizar investimentos produtivos capazes de colocar os calçados fabricados em condiç̃es de competir num mercado cada vez mais competitivo. Confirma esta idéia o resultado obtido no que diz respeito à necessidade de uma escala mínima de produção, que recebeu a terceira maior nota $(5,78)$.

A barreira que recebeu a segunda nota mais elevada foi a marca conhecida 
$(6,00)$. Esta dificuldade pode ter se manifestado porque muitas empresas da região não comercializam seus calçados com uma marca definida, sendo que, no caso de algumas empresas exportadoras, os calçados não são sequer identificados como produtos brasileiros porque não levam a marca do fabricante e sim do atacadista responsável pela importação.

A dificuldade em encontrar mão-de-obra especializada foi considerada, dentre os demais, um dos maiores empecilhos nas empresas pesquisadas (nota 5,67), demonstrando que, apesar de toda infraestrutura destinada ao treinamento dos recursos humanos e da longa convivência da população local com o processo de fabricação, os empresários do setor ainda consideram uma dificuldade encontrar pessoas qualificadas para utilizarem no processo produtivo.

c) Diferenciação: o setor calçadista é, devido às características do produto, um ramo em que a diferenciação está presente ${ }^{4}$. Em especial, destaca-se que a diferenciação ocorre devido às variações da moda, que afetam diretamente as características do calçado fabricado. Para o setor calçadista, além de ser uma variável estrutural, a diferenciação é uma estratégia que merece ser perseguida, pois o setor atua em um segmento de mercado que fabrica calçados numa faixa intermediária de preços. Assim, a diferenciação se torna, além de um aspecto estrutural, também uma estratégia importante. Na pesquisa de campo, procurou-se observar não apenas a diferenciação dos produtos, já que isso é comumente observado nas empresas do setor, mas também a predominância de estratégias de custos e especialização em nichos específicos de mercado (enfoque), conforme o modelo de Porter (1986)

\section{TABELA 2: ESTRATÉGIAS DE REDUÇ̃̃o DE CUSTOS, DIFERENCIAÇ̃̃o}

\section{E ENFOQUE}

\begin{tabular}{c|cccccc}
\hline \multicolumn{7}{c}{ Número de empresas por estratégia } \\
\hline & $\begin{array}{l}\text { Estra- } \\
\text { tégia } \\
\text { gené- } \\
\text { rica }\end{array}$ & $\begin{array}{l}\text { Dife- } \\
\text { rencia- } \\
\text { ção e } \\
\text { Custos }\end{array}$ & $\begin{array}{l}\text { Diferen- } \\
\text { ciação e } \\
\text { Enfoque }\end{array}$ & $\begin{array}{l}\text { Custos } \\
\text { e enfo- } \\
\text { que }\end{array}$ & $\begin{array}{l}\text { Cus- } \\
\text { tos e } \\
\text { enfo- } \\
\text { que }\end{array}$ & Total \\
\hline $\begin{array}{c}\text { Diferencia- } \\
\text { ção } \\
\begin{array}{c}\text { Redução de } \\
\text { custos }\end{array}\end{array}$ & 1 & 1 & 2 & & 4 & 8 \\
$\begin{array}{c}\text { Enfoque } \\
\mathrm{N}^{\circ} \text { de em- } \\
\text { presas }\end{array}$ & 1 & 1 & 2 & 6 & 4 & 12 \\
\hline
\end{tabular}

Fonte: Pesquisa de campo

4 Confirmam a idéia de que o setor calcadista apresenta uma estrutura que propicia a diferenciaç̃o, autores como Vechhio (2004), Coutinho et.al. (1993), entre outros.

79 Revista de Economia, v.40, n. 3 (ano 38), p. 68-90, set/dez. 2014. Editora UFPR
Pelo que se pode observar na tabela, os resultados demonstram que as três estratégias são pouco utilizadas de forma isolada, pois apenas uma empresa utiliza-se exclusivamente da diferenciação, outra utiliza-se unicamente da estratégia de redução de custos, enquanto três empresas optam pela busca de novos nichos de mercado. No entanto, a maioria das empresas pesquisadas (13 das 18 empresas) opta pela utilização de duas ou três estratégias, destacando-se, principalmente, a redução de custos aliada à busca de novos nichos de mercado, com seis delas fazendo uso desta combinação. Chama a atenção o fato de que quatro das empresas pesquisadas afirmaram que se utilizam das estratégias de diferenciação, custos e enfoque, quando ameaçadas pela concorrência e uma emprega a redução de custos e diferenciação. Contudo, utilizar a redução de custos juntamente com a diferenciação não é aconselhável, pois, como destaca Porter (1986), quando uma empresa adota ambas, ela se situa no meio termo, podendo obter baixa rentabilidade por perder os clientes que compram em grandes volumes a baixos custos ou por perder negócios que geram altos lucros para outras empresas que enfocaram a estratégia de diferenciação, agregando maior valor ao produto.

De uma forma geral, pode-se dizer que a estratégia preferida pelas empresas do setor é a de enfoque, com 15 empresas utilizando-se dela. Contudo, comparando-se unicamente as estratégias de diferenciação e custos nas empresas, existe uma predominância da última em relação à primeira, pois 12 empresas fazem uso da estratégia, enquanto 8 optam pela diferenciação.

d) Integração Vertical: a integração vertical ocorre quando uma firma passa a realizar tarefas que antes eram feitas através do mercado. Esse processo é abordado na visão da Nova Economia Institucional (N.E.I) e tem nos trabalhos de Coase e Williamson os principais estudos. O primeiro autor mostra que a existência de empresas se deve aos custos de transação presentes no mercado, o que faz com que as atividades produtivas sejam realizadas por essa organização e não unicamente via mercados (Coase, 1993). Já Williamson avança nas idéias apresentadas em Coase e mostra que em determinados momentos a integração vertical é utilizada pelas empresas, que preferem não utilizar o mercado devido à existência da incerteza e das especificidades dos ativos transacionados (Williamson, 1989; 1999). Assim, como as empresas calçadistas utilizam-se de insumos com grau baixo de especificidade (que facilmente podem ser obtidos na região), a integração vertical não se apresenta como uma característica estrutural da indústria. Além da especificidade dos ativos transacionados, a própria organização da indústria calçadista desestimula a integração vertical, pois pelo fato da maioria das empresas fazerem parte de um cluster, espera-se que adquirir matérias-primas dos fornecedores seja mais viável do que a fabricação própria. Foi exatamente o que se constatou nos dados obtidos mediante a aplicação dos questionários. Observa-se que apenas uma, das 18 empresas pesquisadas, fabrica alguma matéria-prima utilizada na produção de calçados. 
e) Diversificação da produção: a diversificação da produção pode ocorrer na própria indústria, quando a empresa fabrica diferentes tipos de calçados, ou pode ser direcionada para indústrias diferentes, quando a empresa passa a fabricar, além de calçados, outros tipos de produtos. O tipo de diversificação que mais interessa para o setor é a que ocorre dentro da própria indústria. Nesse caso, a Abicalçados (2001) afirma que a indústria brasileira é conhecida por fabricar praticamente todos os tipos de calçados e a pesquisa de campo demonstrou que quase todas as empresas pesquisadas utilizam-se de estratégias de diversificação da produção. Apenas uma empresa, do total pesquisado, não faz uso da estratégia. Devido as suas especificidades, as empresas podem, sem maiores custos, fabricar muitos tipos de calçados porque o processo sofre poucas alterações quando se migra da produção de um tipo de calçado para outro.

\subsection{Conduta (estratégias) de mercado}

a) Propaganda: trabalhos de Gorini e Siqueira (2002), Coutinho et. al. (1993) e Azevedo (2004) transparecem que a estratégia de propaganda é pouco utilizada nas indústrias calçadistas do Brasil, o que dificulta o estabelecimento de uma marca específica para as empresas, uma vez que muitas delas acabam incumbindo os agentes externos dessa tarefa. A dificuldade no estabelecimento de uma marca própria é um aspecto que pode ser determinante no poder de precificação das empresas. Nesses termos, a propaganda e o estabelecimento da marca são estratégias de diferenciação dos produtos, que oferecem maior poder de negociação frente aos consumidores (a la Porter). Os dados obtidos com a pesquisa de campo confirmam essa posição. Ou seja, dentre as empresas pesquisadas, apenas 7 apresentam gastos com propaganda dos seus calçados, o que pouco diferencia os produtos e ainda coloca as empresas como dependentes dos comerciantes de calçados. Das empresas que afirmaram possuir gastos com propaganda, apenas 3 estão procurando aumentar esses investimentos, refletindo a fragilidade das fabricantes em relação a esse aspecto.

b) Pesquisa e desenvolvimento ( $P \& D)$ : por ser um setor significativamente influenciado pelas variações da moda, os investimentos em P\&D são uma importante estratégia para o setor alcançar melhor desempenho. Nas empresas pesquisadas, a maioria delas (11 empresas) apresenta gastos com pesquisa $\mathrm{e}$ desenvolvimento de produtos. Desse total, 7 empresas ainda afirmam que os gastos estão aumentando. Os resultados confirmam a idéia de que as empresas calçadistas estão dando maior importância aos investimentos em P\&D. Pode-se dizer que existe o reconhecimento dos empresários do setor de que esta conduta é uma importante ferramenta competitiva, pois é através dela que as empresas poderão ser capazes de gerar inovações, tanto em termos de produto quanto no processo produtivo, o que possibilitará melhorar seus níveis de qualidade e produtividade e, conseqüentemente, o posicionamento da indústria no mercado nacional e mundial.

c) Determinação de preços: estudos sobre determinação de preços têm uma longa trajetória na teoria econômica. No âmbito da organização industrial, e de um ponto de vista crítico à abordagem microeconômica, a determinação de preços foi estudada por Hall e Hicth (1986) nos anos 30. Os autores demonstraram que, ao invés da precificação com base na maximização dos lucros (igualdade entre Receita Marginal e Custo Marginal), as empresas procuravam determinar os preços adicionando uma margem aos custos de produção (mark-up). Contudo e de uma forma geral, pode-se afirmar que quanto maior o poder de monopólio de uma firma, maior a capacidade de praticar preços mais elevados e, conseqüentemente, de obter maiores lucros. Do contrário, quanto maior a concorrência, menor a capacidade de influenciar o preço, uma vez que ele independe da vontade do empresário. Para uma indústria com baixo grau de concentração, determinar preços depende capacidade de diferenciação das empresas. Quanto à aplicação da pesquisa, do total de empresas que responderam ao questionário, procurou-se observar o poder das empresas no processo de fixação de preços. Nesse caso, foi perguntado qual critério predomina na precificação, se a negociação, o preço de mercado, a determinação de preços pelo comprador ou efetivamente pelo vendedor. Do total de empresas, 11 afirmaram que predomina a negociação entre comprador e vendedor, 5 que predomina o preço de mercado, uma afirmou que predomina a fixação de preço pela empresa vendedora e outra que predomina a fixação de preços pelo comprador. Portanto, quanto a esse critério, as empresas pesquisadas parecem pouco vulneráveis.

d) Investimentos em tecnologia: Vieira (2002) afirma que, apesar do setor calçadista ter se desenvolvido com baixa capacitação tecnológica, nos últimos anos o setor apresenta um aumento no volume de investimentos em modernização produtiva, o que tem colocado algumas empresas brasileiras em patamar de desenvolvimento produtivo semelhante às mais desenvolvidas do mundo. Tendência análoga pode ser observada na região do Vale dos Sinos, onde a maioria das empresas pesquisadas, 50\% delas (9 empresas), afirmam que seus investimentos em máquinas e equipamentos para fabricação de calçados tendem ao crescimento. Dentre os respondentes em que os níveis de investimentos estão constantes (8 empresas), dois julgam não ser o momento para aumentar nem para reduzir os gastos, ou porque fizeram atualização recente de todo seu equipamento, ou porque acreditam que seu nível de investimentos atual é satisfatório. Apenas uma empresa afirmou que seus investimentos em máquinas e equipamentos estão diminuindo e a razão apontada é que ela realiza investimentos de acordo com a sua necessidade, o que atualmente não é o caso. Desta forma, pode-se dizer que a empresa só não está investindo em modernização produtiva porque já está operando com a tecnologia que acredita ser adequada. Isto evidencia, ao menos no que se refere ao universo pesquisado, a importância da modernização produtiva no setor, pois a maior parte das empresas está aumentando as aplicações 
em máquinas e equipamentos e transformando isso em uma estratégia para melhorar a atuação no mercado.

e) Acordos de cooperação: no que diz respeito às estratégias de mercado, cabe ainda considerar a possibilidade de acordos de cooperação entre as empresas. Embora essa conduta esteja mais relacionada a mercados oligopolistas, onde as práticas de acordos são nocivas à sociedade, em um setor de baixa concentração, a cooperação entre as empresas, ao surgir como estratégias de produção ou exportação, pode ser considerada uma ação competitiva recomendável para aumentar a eficiência do setor. O que chamou a atenção nas empresas pesquisadas foi o a baixa ocorrência desse tipo de estratégia. Por ser um cluster esperava-se que os resultados demonstrassem alta incidência de cooperação entre empresas fabricantes. No entanto, quase todas as empresas pesquisadas (17 delas) afirmaram que não realizam acordo com as demais fabricantes de calçados.

f) As fusões e aquisições: num setor pouco concentrado como o calçadista, a realização de fusões e/ou aquisicões por empresas de determinado segmento pode ser uma alternativa viável para melhorar sua posição de mercado, principalmente quando estas não possuem escala suficiente para competir Do total de empresas que responderam a pesquisa de campo, 3 delas realizaram fusões ou aquisições com outras empresas do setor. No universo de 18 empresas respondentes, o fato de 3 adotarem esta estratégia representa um número bastante significativo, principalmente porque todas elas realizaram fusões ou aquisições respectivamente em 1999, 2000 e 2002. Isto demonstra que aumentar a escala é uma necessidade no setor e as fusões e aquisições parecem estar recebendo maior atenção nos últimos anos, quando as empresas estão mais vulneráveis à concorrência externa.

\subsection{Desempenho de Mercado: alguns indicadores para o} setor calcadista gaúcho

Os últimos anos têm sido preocupantes para o setor calçadista do estado. O aumento da concorrência interna e externa, as flutuações do câmbio e a saída de muitas empresas calçadistas do Rio Grande do Sul em direção a outras regiões do país têm causado preocupações quanto ao atual desempenho da indústria. Os gráficos a seguir apresentam o nível de exportações do estado, já que historicamente foi uma indústria voltada ao mercado externo.
FIGURA 3: EXPORTAÇÕES FÍSICAS DE CALÇADOS

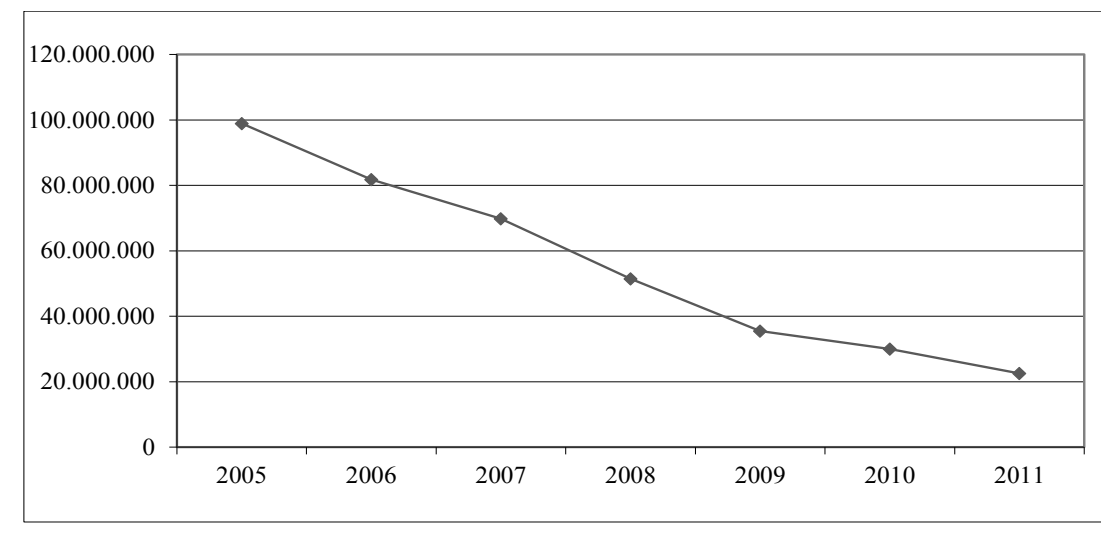

Fonte: Abicalçados

\section{FIGURA 4: VALOR DAS EXPORTAÇÕES GAÚCHAS DO RS}

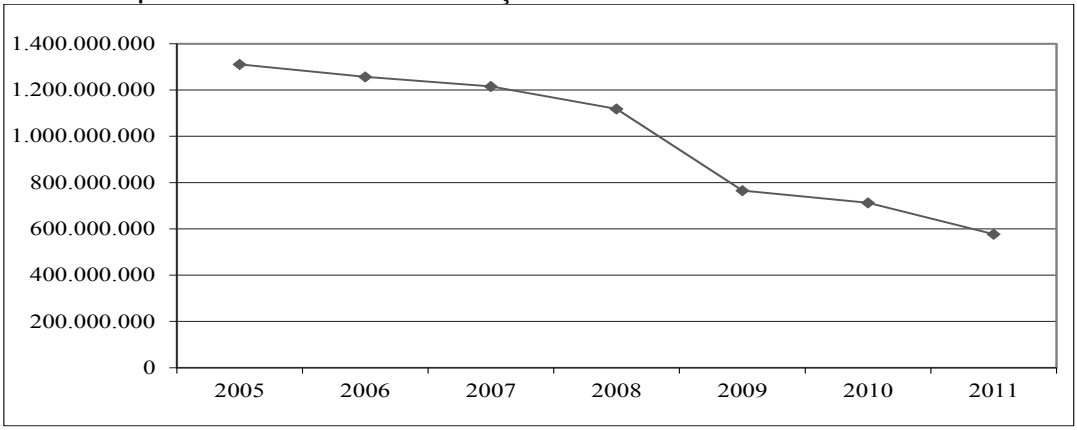

Fonte: Abicalçados

Quando se observa o desempenho das exportações gaúchas de calçados, os dados são surpreendentes, pois em 2005 o volume chegava a quase $100 \mathrm{mi}-$ lhões de pares, mas nos anos seguintes o volume exportado apenas declina. Em 2008 gira em torno dos 50 milhões e, em 2011, reduz-se para 22,5 milhões de pares exportados (Figura 3). Não por acaso reduz-se também a receita com exportações. Conforme se observa na Figura 4, o volume exportado em dólares vem se reduzindo ano após ano. Era de 1,3 bilhão em 2005, caindo para, aproximadamente, 766 milhões em 2009 e chegando ao valor de apenas 577 milhões de dólares em 2011.

Em relação ao país, o estado do Rio Grande do Sul vem perdendo participação tanto no que diz respeito ao volume de pares exportados como no que tange a receita com exportações. Em 2005 era responsável por praticamente $70 \%$ do valor exportado de calçados. Esse percentual cai para algo em torno de 
56\% em 2009 e chega a 44\% em 2011 (Figura 5). Em relação às exportações físicas, os números são ainda mais significativos. Em 2005 o estado era responsável por mais de 50\% das exportações físicas do produto, enquanto em 2011 esse montante se aproxima dos 20\%. Os dados preliminares para 2012 demonstram que a situação do setor continua delicada.

FIGURA 5: EXPORTAÇÕES FÍSICAS E VALOR DAS EXPORTAÇÕES DE CALÇADOS DO ESTADO EM RELAÇÃO DO BRASIL

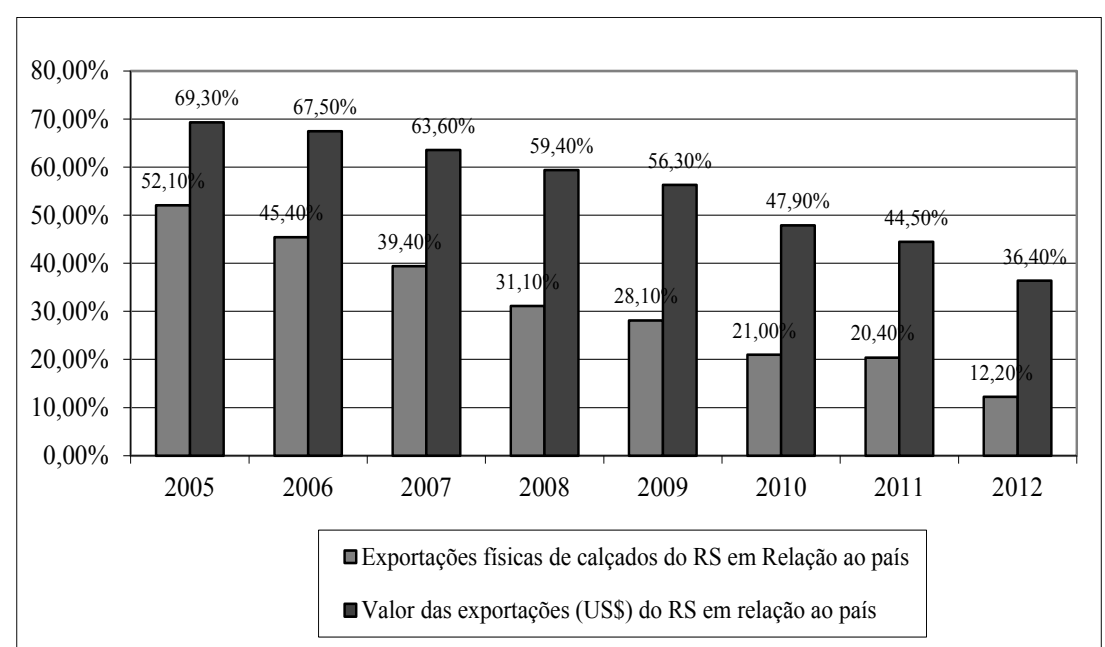

Fonte: Abicalçados

A crise vivenciada pelo setor calçadista se reflete no número de empresas existentes no estado. A série de dados disponibilizada pela Abicalçados mostra que o número de empresas em 1997 era de 1.823, chegando a 2.773 em 2001 e 3.419 em 2005. Em 2007 reverte-se a tendência e se observa redução no número de empresas do setor, chegando a 2.775 firmas. Em 2009 o número de empresas era de 2.762 .

Não espanta, portanto, que os empregos estejam em declínio. O setor, beneficiado pela desvalorização cambial de 1999, de menos de 100 mil empregados em 1998, chega próximo aos 130.000 em 2001 (Abicalçados, 2012). No entanto, de 2001 a 2003 observa-se certa estagnação no volume de empregos, quando os mesmos ficam em torno dos 130.000 para, em 2004, ultrapassarem os 140 mil empregos. Em 2006 o desempenho quanto à geração de empregos se torna comprometido, pois o número de empregados reduz-se para 116.524 A tendência de queda se confirma quando se observam os dados de 2007, quando o emprego cai para 111.966, e de 2009, quando atinge 110.766.

Se a queda no volume de emprego fosse acompanhada por aumentos na produção física de calçados, o indicativo não seria tão grave já que a indústria teria ganhos de produtividade. No entanto, dados do IBGE (2012) para produção de calçados e artigos de couro no estado, demonstram que a queda do emprego foi acompanhada pela queda na produção. Desde o ano 2000, apenas em dezembro de 2010 e dezembro de 2002, a produção acumulada supera a do ano imediatamente anterior. Para citar apenas dois anos, em dezembro de 2009 a produção representava apenas $80 \%$ da produção de 2008. No final de 2011 foi produzido $93 \%$ da produção de 2010. Os decréscimos seguidos em termos de produção confirmam os problemas vivenciados pela indústria nos últimos anos.

Apesar do comportamento comprometedor da série de indicadores apresentados, chama à atenção a evolução do preço médio dos calçados exportados pelo Rio Grande do Sul, fator que impediu uma queda ainda maior na receita de exportações. O preço médio dos calçados gaúchos que era de 13,25 dólares em 2005 ultrapassa os 20 dólares em 2008 (21,71 dólares o par), chegando, segundo dados preliminares da Abicalçados, a 26,63 dólares em 2012 (Figura 6). O que mais chama atenção nesses dados é que o preço médio do calçado gaúcho tem se afastado significativamente do preço médio do produto brasileiro. Em 2005 a diferença era de US \$ 3,28, aumentando para US\$10,36 em 2008 e chegando a US $\$ 13,97$ em 2011. Embora os dados sejam preliminares, no ano de 2012 a diferença é de 17,69 dólares na média.

FIGURA 6: PREÇO MÉDIO DOS CALÇADOS GAÚCHOS E BRASILEIROS EM DÓLARES

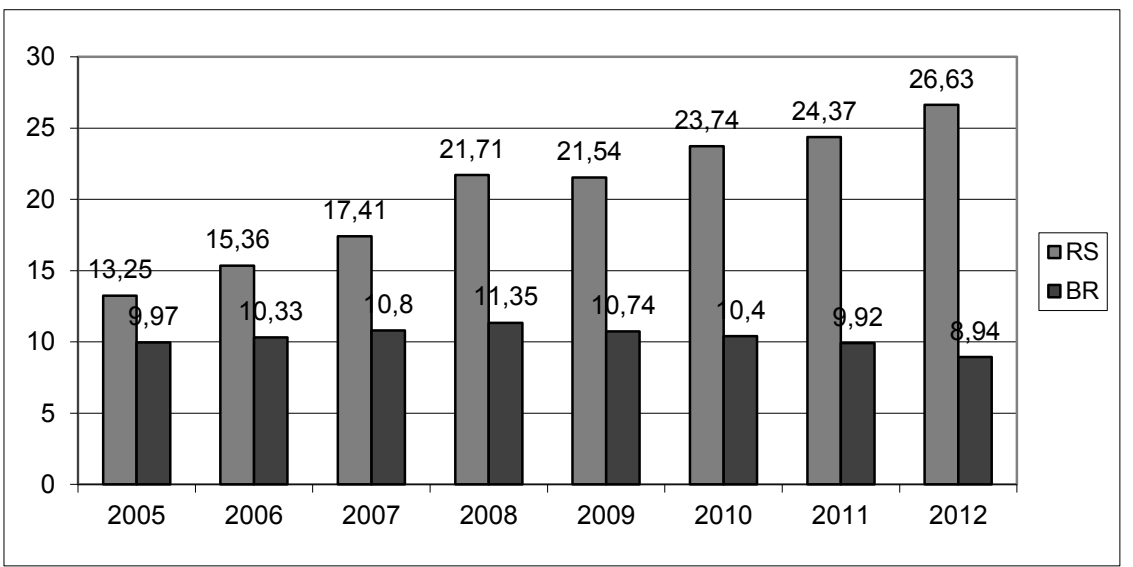

Fonte: Abicalçados

Essa grande variação, embora com todas as dificuldades verificadas na indústria, sugere que as fábricas podem estar inserindo-se em um segmento de mercado mais diferenciado. Nesses termos, parece que os esforços despendidos pelas empresas gaúchas no sentido de aumentar a atratividade dos seus 
produtos, de forma a minimizar os problemas enfrentados pelas variações cambiais, estão surtindo efeitos. Tais dados parecem, então, sugerir que certa transformação estrutural pode estar ocorrendo nos últimos anos. Confirma essa idéia o fato de que praticamente todas as empresas pesquisadas no Vale dos Sinos/RS (17 num total de 18 empresas) afirmaram que utilizam algum sistema de controle da qualidade nos calçados fabricados, o que ilustra a preocupação com a diferenciação do produto.

\section{Considerações Finais}

Este trabalho teve o objetivo de fazer uma caracterização do setor calçadista utilizando-se do modelo E-C-D. Para isso foram utilizados dados secundários referentes à indústria gaúcha, assim como informações de questionários enviados as empresas calçadistas do Vale dos Sinos/RS que se encontravam cadastradas na Abicalçados. Os resultados mostraram que a indústria gaúcha vem passando por significativos problemas ao longo dos últimos anos, o que ficou claro nas análises sobre o desempenho do setor. Quanto a sua estrutura industrial, os resultados mostram que a concentração, medida pelos índice $\mathrm{HH}$ e $\mathrm{Cr}$ aumentou do ano de 1991 para 1998, voltando a reduzir-se em 2008 Parece que os problemas cambiais, a concorrência dos calçados importados e a migração para outras regiões do país, estão fragmentando ainda mais o setor

Embora seja um setor tradicionalmente apontado como possuidor de baixas barreiras à entrada, os resultados da pesquisa de campo demonstram que os empresários do setor calçadista reconhecem a necessidade de investimentos iniciais elevados e uma alta escala produtiva para fabricação de calçados. Isso demonstra, novamente, que o ambiente extremamente desfavorável dos últimos anos tem causado a percepção de que são precisos grandes esforços para competir nesse mercado que não aceita formas de produção rudimentares. Trata-se ainda de um setor que, por suas características produtivas, fabrica produtos diferenciados. Sobre esse aspecto, apesar das empresas afirmarem que tem feito esforços significativos na redução de custos, observa-se que os preços médios dos calçados gaúchos vêm aumentando, indicando que estão sendo fabricados calçados de maior valor agregado. Essa idéia é confirmada quando se observa o fato das empresas pesquisadas possuírem certa capacidade de negociação junto aos clientes.

Quanto à conduta de mercado, é possível constatar o esforço realizado pelas empresas para manterem-se competitivas. A pesquisa de campo apontou que a maioria das fábricas realiza investimentos em Pesquisa e Desenvolvimento de novos produtos. Da mesma forma, mesmo com problemas financeiros, uma boa parte das empresas têm procurado aumentar os investimentos em tecnologia, fator importante para concorrer num mercado em que a diferenciação é fundamental. Outro aspecto que chamou a atenção nas empresas pesquisadas é a realização de fusões e aquisições, o que confirma a idéia de que as empresas precisam ampliar sua capacidade para concorrer no cenário macroeconômico que se formou nos últimos anos. Por outro lado, as empresas ainda despendem pouca atenção à cooperação e aos investimentos em propaganda. $\mathrm{O}$ primeiro ponto é compreensível em função da aglomeração industrial. Já o segundo, aliado a inexistência de uma marca própria, merece mais atenção por parte das empresas por ser fator importante de competitividade.

Enfim, o setor calçadista do estado e do Vale dos Sinos, apesar de seu bom desempenho histórico e da sua importância para economia da região, tem passado por sérias dificuldades que se expressam em algumas variáveis de desempenho. Apesar do empenho das empresas do setor em termos de conduta competitiva, fatores externos dos quais a indústria possui pouco ou nenhum controle parecem estar falando mais alto e "destruindo" uma competitividade construída em décadas. Esse é o momento de fazer uso da cooperação entre empresas e reivindicar políticas públicas específicas para melhorar o desempenho do setor. Estudos futuros em termos do modelo E-C-D podem fazer análises do impacto das políticas macroeconômicas e setoriais sobre o desempenho do setor calçadista e, nesse caso, serem mais específicos em demonstrar como a competitividade do setor tem sido destruída pelo descaso das autoridades. 


\section{Referências Bibliográficas}

Abicalçados. Associação Brasileira das Indústrias de Calçados. Disponível em: www.abicalçados.com.br. Acesso em: 10 de Março de 2012.

Rumo ao mercado internacional. $1^{\circ}$ ed. Novo Hamburgo: Abicalçados, 2001. disponível em www.abicalcados.com.br. Acesso em: 20 de Ago. de 2004

Azevedo, P. F. Competitividade da cadeia couro e calçados. Fórum de competitividade da cadeia couro-calçados. Relatorio do programa de estudos e negócios do sistema agroindustrial (PENSA) ao ministério do desenvolvimento, indústria e comércio exterior. 2004 Disponível em www.desenvolvimento.gov.br . Acessso: 20 de jul. de 2004.

Bain, J. S. Industrial organization. New York: John Wiley, 1968.

Cabral, L. Economia Industrial. Portugal: Mc-Graw-Hill, 1994.

Cadastro Empresarial Do Rio Grande Do Sul. Fiergs, 1991, 1998 e 2008.

Carlton B.; Perloff, J. Modern industrial organization. Harper Collins, 1994.

Coase, R.. The nature of the firm: orgins, evolution, and development. New York/ Oxford: Oxford University, 1993.

Coutinho, L. G. et. al. Competitividade da indústria de calçados. Estudo da competitividade da indústria brasileira. Campinas, 1993. Disponível em www.mct. gov.br/publi/compet/nts. Acesso: 25 de jul. de 2007.

Fee. Fundação de Economia e Estatística, 2012. Disponível em http://www.fee tche.br/sitefee/pt/content/resumo/pg_coredes_detalhe.php?corede $=$ Vale $+\mathrm{d}$ o+Rio+dos+Sinos. Acesso 23/03/2012.

Ferraz, J. C.; Kupfer, D.; Haguenauer, L. Made in Brazil: desafios competitivos para a indústria. Rio de Janeiro: Campus, 1997.

Gil. A. C. Métodos e técnicas de pesquisa social. São Paulo: Atlas, 1999.

Gorini, A. P.; Siqueira, S. H.; Franco, R. F.; Turano, C. O Setor de calçados no Brasil. Setor calçados, 2000. Disponível em www. bndes.br. Acesso: 25 de set. de 2008

Gorini, A. P.; Siqueira, S. H. Complexo coureiro-calçadista nacional: uma avaliação do programa de apoio BNDES. 2002. Disponível em www.bndes.gov.br/ conhecimento/Bnset/set904.pdf. Acesso: 20 de jul de 2007.

Hall, R.l.; Hitch, C.j. 1986. A teoria dos preços e o comportamento empresarial. Literatura Econômica, 8(3):43-78.

Holanda Filho, S. B. Estrutura industrial no Brasil: concentração e diversificação. IPEA/INPES, 1983.

Ibge. Sistema gerenciador de séries temporais. Rio de Janeiro, 2012. Disponível em: <https://www3.bcb.gov.br/sgspub/localizarseries/localizarSeries.do?met hod=prepararTelaLocalizarSeries>. Acesso em: 20 Mar. 2012.

Kon, A. Economia industrial. São Paulo: Nobel, 1994.

Kupfer, D. Padrões de concorrência e competitividade. Anais da Anpec, 1992.

Lemos, C.; Palhano, A. Arranjo produtivo coureiro-calçadista de Campina Grande/ $\mathrm{PB}$. Arranjos e sistemas produtivos locais e as novas políticas de desenvolvimen- to industrial e tecnológico. Nota técnica $\mathrm{N}^{\circ}$ 22. Rio de Janeiro: IE/UFRJ, 2000.

Mason, E. (1939). Price and Production Policies of Large-Scale Enterprise. American Economic Review, No 29. Vol. 1. P. 61-74.

Porter. M. Estratégia competitiva: técnicas para análise de indústrias e da concorrência. $14^{\circ}$ ed. Rio de Janeiro: Campus, 1986.

Resende, M.; Boff, H. Concentração industrial IN KUPFER, D. e HASENCLEVER, L (Org). Economia industrial: fundamentos teóricos e práticas no Brasil. Rio de Janeiro: Campus, 2002.

Rosa, L.c. Contribuição metodológica para análise estrutural de sistemas agroindustriais: um estudo de segmento produtor de vinhos finos do Rio Grande Sul. 2001. Tese (Doutorado em Engenharia de Produção)- Universidade Federal de Santa Catarina, Florianópolis, 2001.

Sebrae. Serviço Brasileiro de Apoio às Micro e Pequenas Empresas, 201o. Disponível em www. sebrae.com.br. Acesso em 12 de mar. de 2010.

Scherer, F.m.; Ross, D. Industrial market structure and economic performance. 3 ed. Chicago: Raud Mc Nally \& Co, 1990.

Vargas, M. A.; Alieve, R. M. Arranjo produtivo coureiro-calçadista do Vale dos Sinos (RS). Arranjos e sistemas produtivos locais e as novas políticas de desenvolvimento industriale tecnologico. Nota técnica 19 . Rio Disponível em www.finep.gov.br. Acesso: 15 de set. de 2004.

Vechhio, R. A. Autonomia para a competitividade: o futuro da indústria coureiro-calçadista do Rio Grande do Sul, 2004. Disponível em: www.read.adm. Ufrgs. br/read. Acesso: 01 de mar. de 2004.

Vieira, L. F. Estratégias tecnológicas da indústria calçadista nacional. Boletim Bimestral da Associação dos Analistas de Comércio Exterior. No 01 - Julho e Agosto /2002. Disponível em www. http://sisnet.aduaneiras.com.br. Acesso: 19 de jul de 2004

Williamson, O. E. Transaction Cost Economics. In: Handbook of industrial organization. Amsterdam: Elsiever, 1989.

The economics and transaction costs. New York: Free Press, 1999. 